\title{
The Impact of Population Growth on the Future Air Traffic Demand in Singapore
}

\author{
S.M. Phyoe*, N.Y. Nguyen, S. Aneeka, Z.W. Zhong \\ School of Mechanical and Aerospace Engineering \\ Nanyang Technological University,50 Nanyang Ave 639798, Singapore \\ E-mail:SMPhyoe@ntu.edu.sg \\ www.ntu.edu.sg
}

Keywords: Air Traffic, Forecasting, Traffic Growth, Air Traffic Demand, Singapore, Population.

\begin{abstract}
Forecasting air traffic demands is important when planning for the future density and capacity of a Flight Information Region (FIR). There are many factors that affect air traffic demand such as Gross Domestic Product (GDP), air fare, service level, travel time etc. Our previous study analyzed the relationship between the GDP and air traffic demand and suggested that the GDP has a significant influence on the air traffic demand. This paper further analyzes the relationship between the population growth and air traffic demand. A case study on Singapore FIR and Singapore population was carried out in this work. A model for predicting the future air traffic demand was developed and a long-term forecast was considered in this study. The aim of this study is to improve the previous study and establish more relevant applicable variables. This paper also includes simulations and modeling of the future traffic demand forecasted, using the System for Traffic Assignment and Analysis at a Macroscopic Level (SAAM) tool.
\end{abstract}

\section{Introduction}

The world has been experiencing continuous population growth for the last 55 years. Reports from UN highlighted a continuous increase in global population which is expected to reach between 8.3 and 10.9 billion by 2050 [1] [2]. The population in Singapore has also been continuously increasing with its rising economy. Singapore has seen tremendous development in free-market economy thus attracting more international investments, foreign talents and workers [3]. Singapore has a population of 5.5 million and has the highest population density in the world till 2015 based on official estimates [4]. Population growth can create increase in demand for travel [5] especially in countries like Singapore, where overseas travel has become increasingly popular among the residents [6]. Singapore residents made a total of 4.4 million trips overseas by air and sea in 2001, which was up from 1.6 million trips in 1991 [6]. It represented an annual growth rate of $11 \%$ which was much larger than the population growth rate of Singapore [6]. The analysis also claimed that the frequency of overseas travel among Singapore residents per year was an average of 3.4 trips in year 2000 [6]. The review thus, indicates that population growth is a significant variable in forecasting future air traffic demand.

Our previous study analyzed the relationship of economic variables and air traffic demand and established that GDP could be one of the convincing explanatory variables for forecasting future air traffic volumes [7]. The ARIMAX model was found to be the best approach in the previous study. This study analyzes the impact of 
population on air traffic demand. Models for predicting the future air traffic demand were developed and a long-term forecast was considered in this study.

\section{The Data}

This study uses data on the number of passenger movements from 2003 to 2015 from World Bank and Wikipedia (Singapore Changi Airport) [8] [9] and 2015 December flight plan data for simulation and modeling. Population data from 2003 to 2015 was collected from World Bank and Statistics Singapore [10] [15].

\section{Trend in Changi Airport Passenger Movement}

Figure 1 depicts the number of passengers from 2003 to 2014. The graph indicates a gradual increase in air passenger movements over 11 years except in 2009. An 8.4\%

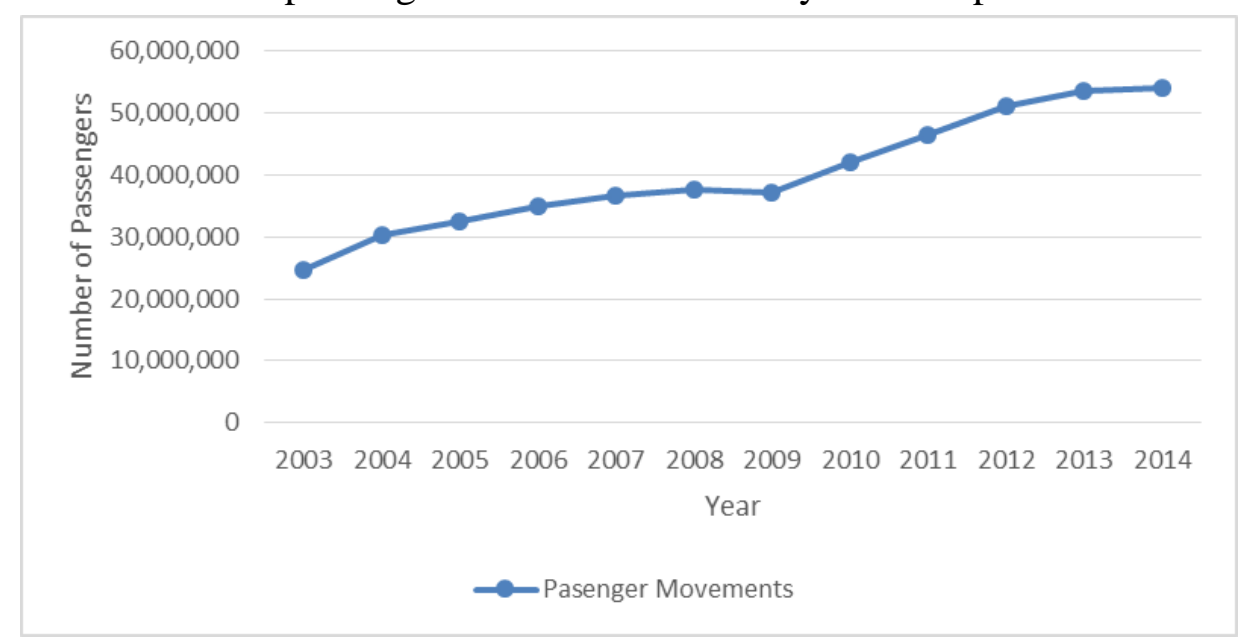

Figure 1. Growth of passenger movements from 2003 to 2014.

average annual growth rate was observed over the last 11 years. It should be noted that this is under the condition of three airport terminals and two runways. Recently, Changi Airport has undertaken initiatives to increase its airport capacity. Two additional terminals are now being constructed, with Terminal 5 planned to be built bigger than the three current terminals [12]. Changi airport has also started developing a third runway that will allow more flights to be handled as the demand for air travel increases [13].

\section{Singapore Population}

Figure 2 shows the total population of Singapore from 2003 to 2015. The curve indicates a gradual linear increase trend except for a steep rise from 2008 to 2009. A 1\% average annual growth rate was observed over the last 12 years. This population data excludes residents who have been away from Singapore for a continuous period of 12 months or longer as at the reference period. 


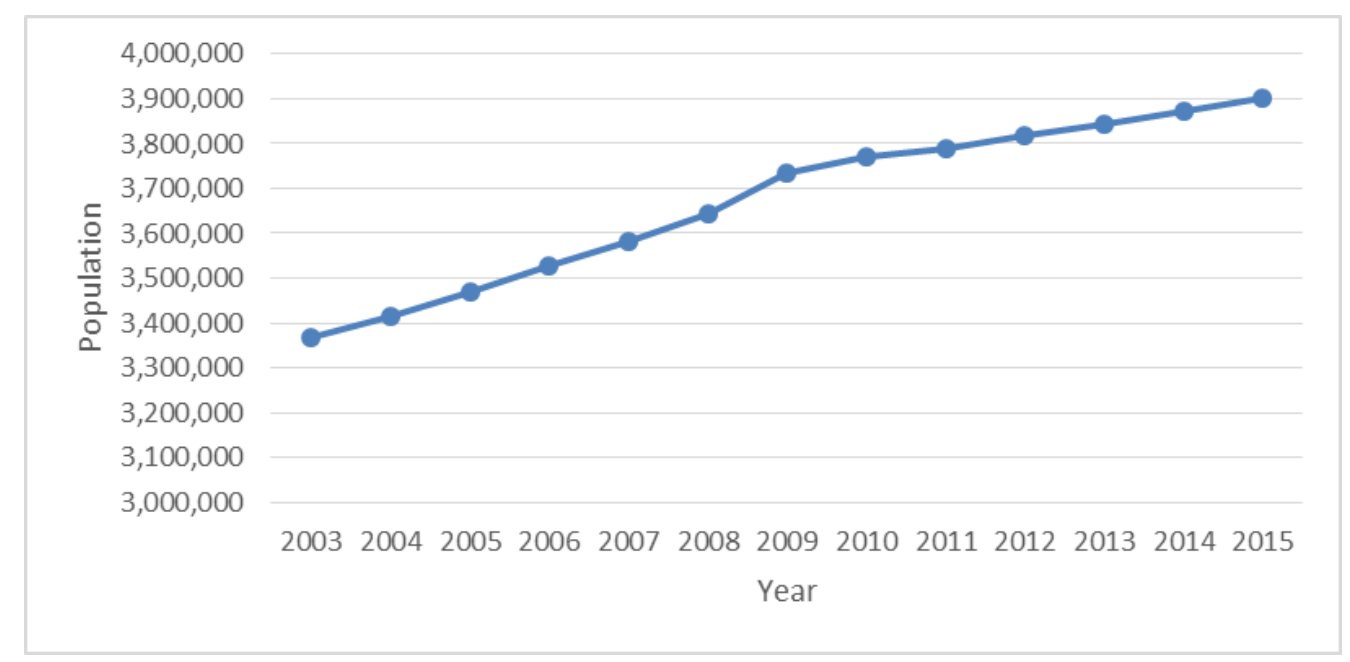

Figure 2. Total Population growth of Singapore

\section{Linear Regression}

Regression analysis is the most common method used for forecasting.[7] Multiple regression is a type of regression method that allows additional factors to be considered in the analysis separately.[7] The hypothesized relationship between the number of passengers and time has the following formula:

$$
\mathrm{Y}=\mathrm{a}+\mathrm{bx}=\mathrm{cy}
$$

where $\mathrm{Y}$ is the number of passengers, $\mathrm{a}, \mathrm{b}$ and $\mathrm{c}$ are constant, $\mathrm{x}$ is time, $\mathrm{y}$ is population.[7]

\section{Results\& Discussion}

The Statistics Singapore Newsletter stated that the adult and the employed person got more propensity to travel overseas. So in this study, we consider analyzing the population of Singapore according to age group. The total population was divided into three groups, which ranges from 10 to 24,25 to 39 and 40 to 54 years old. Figure 3 shows the comparison between the three age groups and total population.

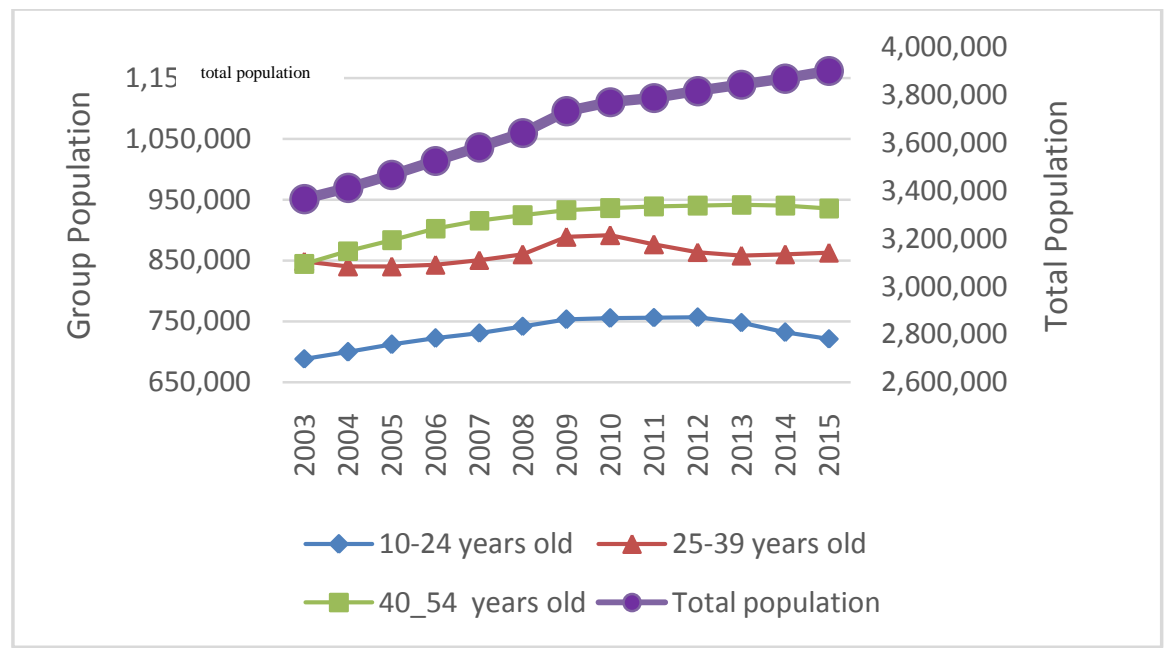

Figure 3. Singapore Population growth by Age Group 
There is continually increase in total population and slightly increase in 40-54 years old group. The age group between 10 to 24 years old and 40 to 54 years old are slightly reduced. According to Table $1, \mathrm{P}$ value, $\mathrm{F}, \mathrm{R}^{2}$, RMSE (root mean square error) and MAPE (mean absolute percentage error) are measured to compare the reliability and accuracy of the variables. Table 1 shows that total population is the best performed variable among these four groups. Therefore, total population can be used as a primary factor that has the most significant impact on the air traffic demand.

Table 1. Comparison of error measurements of different models.

\begin{tabular}{lrllcc}
\hline & RMSE & \multicolumn{1}{c}{ MAPE } & \multicolumn{1}{c}{$R^{2}$} & \multicolumn{1}{c}{ F } & P value \\
\hline $10-24$ years old & 6703022.2 & 10.647 & 0.547 & 12.089 & 0.006 \\
$25-39$ years old & 9134310.5 & 17.49 & 0.159 & 1.895 & 0.199 \\
$40-54$ years old & 4963138.1 & 9.208 & 0.752 & 30.290 & 0.00026 \\
Total population & 3348923.95 & 6.13 & 0.887 & 78.491 & $<0.0001$ \\
\hline
\end{tabular}

The equation that expresses the relationship between the number of passengers and the population and time is shown below:

Passenger Movements $=-144239134.487096+50.4810584367858 *$ Total population

The model has a $\mathrm{R}^{2}$ value of 0.887 , which means it is suitable for expressing the relationship. The number of passengers in 2015 is extrapolated, and p value is less than 0.0001. The result has confirmed the correction of the model. Figure 4 shows the prediction using this model.

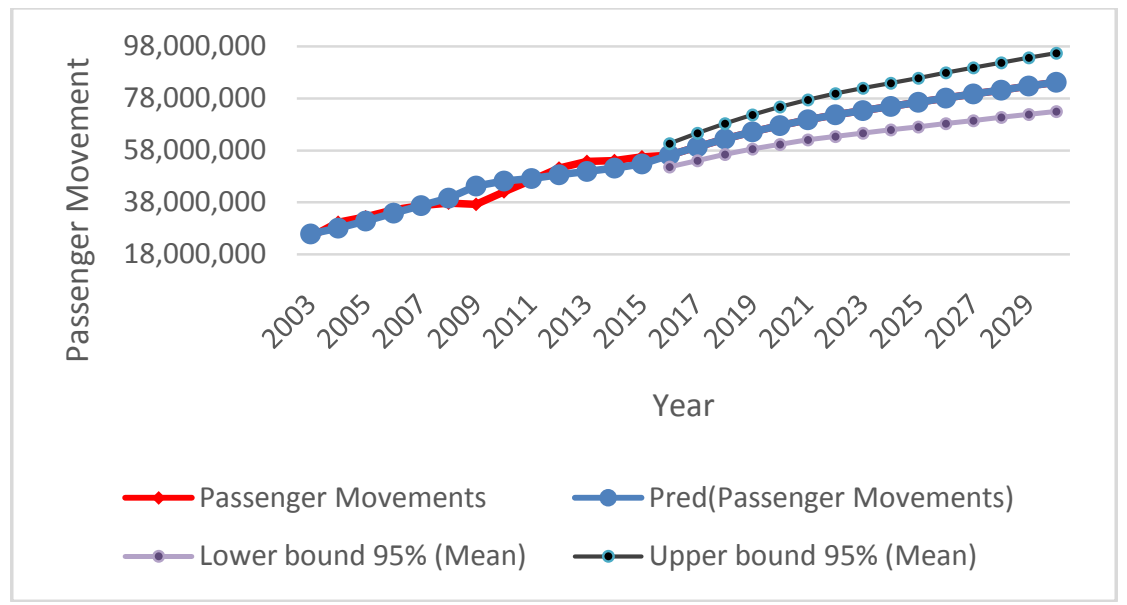

Figure 4. Singapore Changi Airport Passenger Movement Forecasting for next 15 years 


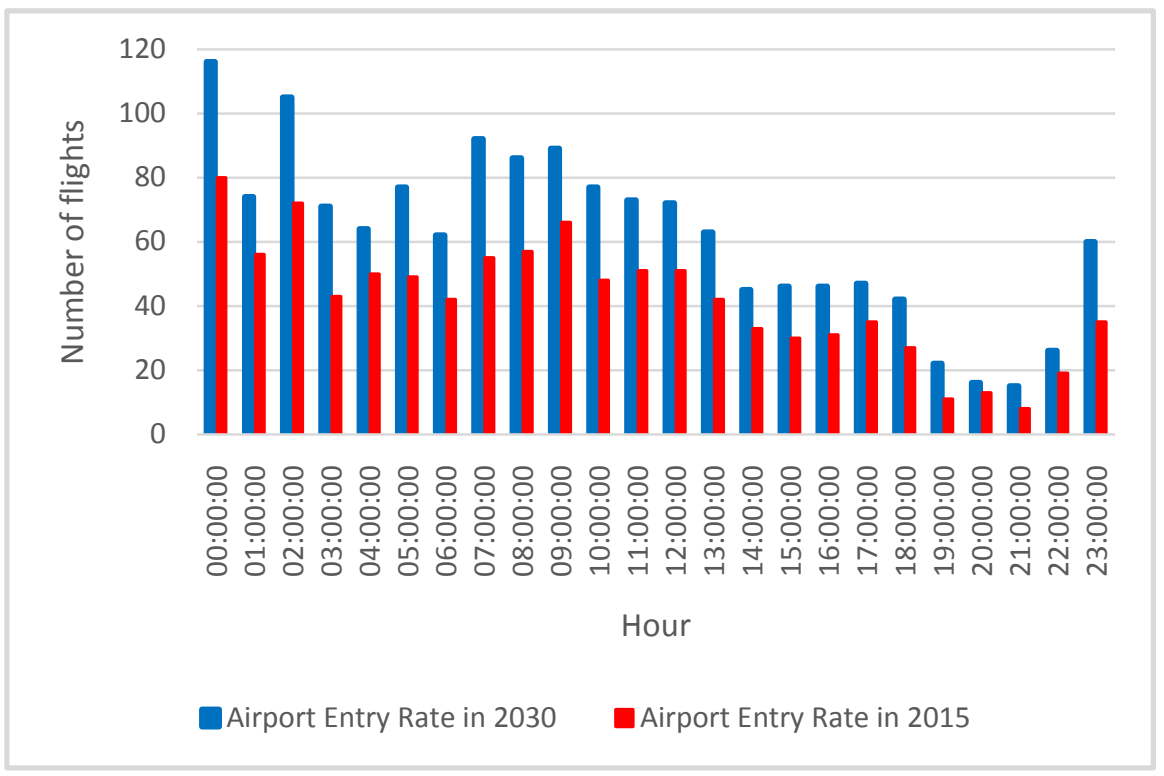

Figure 5. Changi Airport's hourly entry rate comparison between 2015 and 2030.

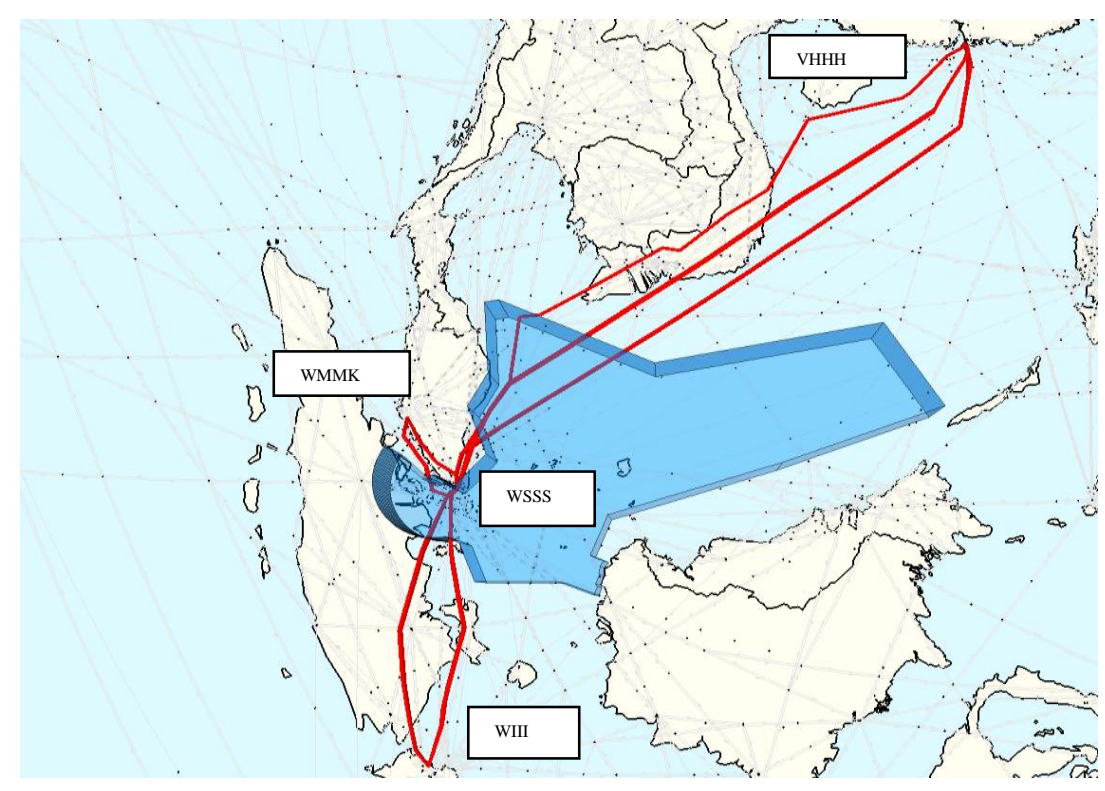

Figure 6. top three airport pairs for Changi airport

The average growth rate from 2016 to 2030 is $3.4 \%$ and the value for lower and upper bound is $2.7 \%$ and $3.6 \%$ respectively. By using the growth rate of $3.4 \%$, Changi airport is estimated to have 1486 flights per day in next 15 years. Figure 5 shows the comparison of the hourly entry rate for Changi airport in 2015 and 2030. It is estimated that the most crowded hour will be around midnight with 116 flights per hour.

Figure 6 shows the top three airport pairs for Changi airport will be Kuala Lumpur/Sepang International Airport, Jakarta International/Soekarno Hatta Airport and Hong Kong Airport with 134, 115 and 75 flights per day.

\section{Conclusion}

The paper has validated the impact of population growth on the air traffic demand in Singapore. This study used age groups and total population as case study variables 
and found out that total population can be used as a variable. The model has shown a good fit to the observed data. By using the result of forecasting, the airport entry rate and top airport pairs were estimated. The work may be helpful for future airport capacity and infrastructure planning. In future, more explanatory variables can be discussed.

\section{Acknowledgement}

This research was sponsored by the ATMRI of NTU and CAAS via ATMRI Project No. 2014-D2-ZHONG for Regional Airspace Capacity Enhancement - ASEAN Pilot.

\section{References}

[1] United Nations, Department of Economic and Social Affairs, Population Division (2013).World Population Prospects: The 2012 Revision, Highlights and Advance Tables. Working. Paper No. ESA/P/WP.228.

[2] World population projected to reach 9.6 billion by 2050 - UN report", UN News Service Section, $2016 . \quad$ [Online]. Available: http://www.un.org/apps/news/story.asp?NewsID=45165\#.V-UHyMnJ0oY. [Accessed: 23- Sep- 2016].

[3] "The World Factbook - Central Intelligence Agency", Cia.gov, 2016. [Online]. Available: https://www.cia.gov/library/publications/the-world-factbook/geos/sn.html. [Accessed: 23- Sep- 2016].

[4] "List of countries and territories by population density", Wikipedia, 2016. [Online].

Available: https://en.wikipedia.org/wiki/List_of_countries_and_territories_by_population_densit y. [Accessed: 23- Sep- 2016].

[5] E. Suryani, S. Chou and C. Chen, "Air passenger demand forecasting and passenger terminal capacity expansion: A system dynamics framework", Expert Systems with Applications, vol. 37, no. 3, pp. 2324-2339, 2010.

[6] T. Lip, Overseas Travel by Singapore Residents, 1st ed. Population Statistics Section Singapore Department of Statistic, 2002.

[7] S.M. PHYOE, R. GUO, Z.W. ZHONG, "AN AIR TRAFFIC FORECASTING STUDY AND SIMULATION", in 4th International Conference on Researches in Science and Technology (ICRST), Kuala Lumpur, Malaysia, 2016.

[8] Air transport, passengers carried | Data", Data.worldbank.org, 2016. [Online]. Available: http://data.worldbank.org/indicator/IS.AIR.PSGR. [Accessed: 23- Sep2016].

[9] "Singapore Changi Airport", Wikipedia, 2016. [Online]. Available: https://en.wikipedia.org/wiki/Singapore_Changi_Airport\#cite_note-58. [Accessed: 23- Sep- 2016].

[10]"Population, total | Data", Data.worldbank.org, 2016. [Online]. Available: http://data.worldbank.org/indicator/SP.POP.TOTL. [Accessed: 23- Sep- 2016]. 
[11]"Statistics Singapore - Publications and Papers - Population", Singstat.gov.sg, 2016. [Online]. Available: http://www.singstat.gov.sg/publications/publications-andpapers/population\#population_and_population_structure. [Accessed: 23- Sep- 2016].

[12] "Changi's T5 to be bigger than 3 current terminals combined", The Straits Times, 2015. [Online]. Available: http://www.straitstimes.com/singapore/transport/changist5-to-be-bigger-than-3-current-terminals-combined. [Accessed: 23- Sep- 2016].

[13]K. KAUR, "\$1.1b contract awarded for 3-runway system at Changi", The Straits Times, 2015. [Online]. Available: http://www.straitstimes.com/singapore/11bcontract-awarded-for-3-runway-system-at-changi. [Accessed: 23- Sep- 2016]. 